\title{
Research Paper: The Effectiveness of Positive Thinking Training in the Quality of Life and Emotion Regulation Among Patients With Multiple Sclerosis
}

\author{
Zahra Nikmanesh $^{1^{*}}$ (D), Lida Mirkazehi² (D) \\ 1. Department of Psychology, Faculty of Education and Psychology, University of Sistan \& Baluchestan, Zahedan, Iran. \\ 2. Aliebne Abitaleb Hospital, Zahedan University of Medical Sciences, Zahedan, Iran.
}

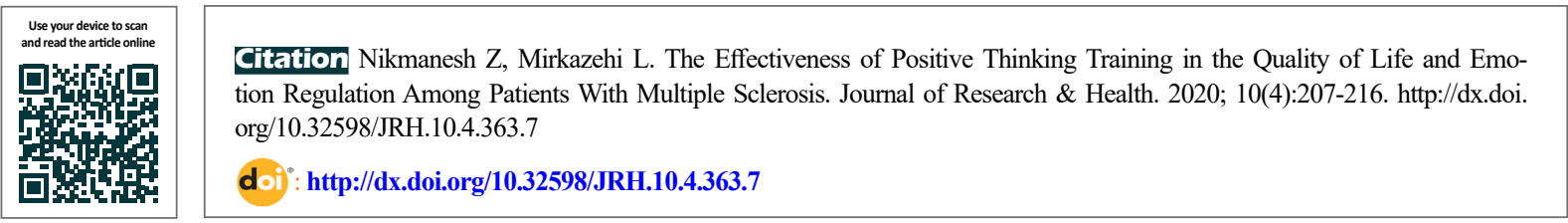

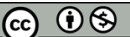

Article info:

Received: 17 Feb 2018

Accepted: 16 Jul 2018

Publish: 01 Jul 2020

Keywords:

Emotion, Multiple

sclerosis, Positive

thinking, Quality of life

\section{A BSTRACT}

Background: Multiple Sclerosis (MS) affects various aspects of a patient's life. This study aimed to investigate the effect of positive thinking training on the quality of life and emotion regulation among patients with MS.

Methods: This research was a quasi-experimental study conducted on a sample of 40 patients selected by convenience sampling method. Eight 90-minute sessions of positive thinking training were held for the experimental group for two months. The Post-test and follow-up were conducted at the end of the sessions and a month later, respectively. Ware and Sherbourne Quality of Life Questionnaire (1999) and Ibanez et al. Self-Regulation Scale (2005) were used for collecting the data. The data analyses were conducted using the analysis of covariance. The inclusion criteria were suffering from MS and being able to read and write. The exclusion criteria were having mental disorders, cognitive disorders, a history of substance addiction, and other neurological disorders.

Results: The results demonstrated a significant difference between the scores obtained by the groups with regard to emotion regulation (Eta-squared $=0.62, \mathrm{P}<0.001$ ). Besides, considering physical health, there was a significant difference between the scores obtained by the groups (Eta-squared $=0.53, \mathrm{P}<0.001$ ), and considering mental health, there was a significant difference between the scores obtained by the groups (Eta-squared $=0.74, \mathrm{P}<0.001$ ).

Conclusion: These results indicated that positive thinking training was effective in improving emotion regulation and promoting quality of life in pre-test, post-test, and follow-up. Authorities are recommended to conduct programs based on positive thinking training to promote emotion regulation and increase MS patients' quality of life. It is recommended that training positive thinking skills be conducted as a regular program at associations and organizations, which support MS patients to promote the levels of quality of life and emotion regulation among these patients.

\footnotetext{
* Corresponding Author:

Zahra Nikmanesh, PhD.

Address: Department of Psychology, Faculty of Education and Psychology, University of Sistan \& Baluchestan, Zahedan, Iran .

Phone: +98 (915) 1404553

E-mail: zahranikmanesh@yahoo.com;nikmanesh@ped.usb.ac.ir.
} 


\section{Introduction}

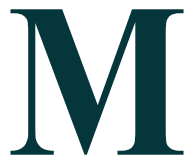

ultiple Sclerosis (MS) is among the most important central nervous system diseases. It is one of the most prevalent neurological diseases in humans and the leading cause of disability in young people so that 2.5 million people suffer from MS all around the world [1]. In Iran, MS is relatively prevalent. The reported prevalence rate of this disease in Iran is lower than its actual rate [2]. According to the MS community statistics in Iran, nearly 40000 people suffer from MS; therefore, this country can be identified as an MS high-risk area [3]. MS is twice as likely to occur in women as in men. The most prevalent age for developing this disease is between 20 and 40 years [4].

Quality of life is one of the most fundamental concepts in positive psychology [5]. The World Health Organization (WHO) defines the quality of life as an individual's perception of his or her status in life in the context of the cultural and value system in which he or she lives and it can be affected by his or her physical, mental, personal beliefs, and social relations conditions [6]. An MS patient encounters numerous issues. These issues limit health promotion activities and, consequently, increase secondary complications and restrictions in having an independent life, which can ultimately bring about negative impacts on the patient's quality of life [7]. These patients' levels of quality of life are influenced by the severity and the duration of the disease, as well as the kind of drugs they take. Nowadays, many governments consider promoting the quality of life as an important and integral component of social and economic development [8].

One of the factors that can affect MS patients' quality of life is emotional self-regulation. Self-regulation is an organized effort to adjust thoughts, feelings, and actions to achieve specific goals. Positive emotions facilitate selfregulation and negative emotions damage self-regulation [9]. Emotion regulation refers to all approaches used to reduce, promote, and enhance emotions. Emotion regulation includes a wide range of conscious and unconscious physical, cognitive, and behavioral processes. Cognitiveemotional regulation refers to conscious cognitive methods and is considered a part of the broader concept of emotion regulation that includes all processes involved in evaluating and modifying emotional responses [10].

Positive psychology seeks to provide a clear image of a good life $[11,12]$. Positive psychology has always sought to identify, describe, and predict happiness and mental wellbeing. The core concepts of this field are improv- ing individuals' wellbeing, identifying positive aspects, and strengthening them for promoting mental health, and helping people to treat their problems if there is any [13, 14]. Training positive thinking skills aiming at strengthening and improving positive relationships with others, promoting positive emotions and behaviors, improving positive cognitions and perceptions, raising people's wellbeing, treating some mental disorders, and increasing self-esteem can be very useful and beneficial [15].

The results of studies demonstrated that positive thinking was significantly and directly related to mental health [16]. Moreover, not only does positive psychology give people tools to reach a desirable level of wellbeing and a high level of quality of life without considering their conditions but also makes it possible to cope with their issues by applying hope, optimism, flexibility, and spirituality [17]. Several studies have shown the effects of positive coping strategies on mental wellbeing [18]. The results of another study indicated that positive thinking training was effective in promoting the level of quality of life among juvenile delinquents [19].

Additionally, the results of a similar study revealed that perceived family support predicted life satisfaction, reduced negative moods and increased positive moods [20]. Research evidence suggested that using positive thinking as a treatment increased mental health and promoted positive relations, emotions, and self-esteem [21-23]. There was a direct significant relationship between emotion regulation and positive thinking training [24]. Furthermore, carrying out positive psychotherapy increases mental wellbeing and quality of life [25] and positive thinking establishes positive relationships with others and creates positive emotions [26].

Several studies have examined the effect of positive thinking training on various groups. Among these studies, the following can be mentioned. A study has shown that positive thinking training increased the levels of resilience and quality of life among cancer patients [27]. The results of a similar study referred to the effect of positive thinking training on the quality of life and mental health of patients in the considered experimental group [28]. Moreover, positive thinking training increases the scores of hope and dimensions of quality of life (physical, mental, and social dimensions) among drug-dependent people [29].

A study has demonstrated that optimism training was effective in promoting psychological wellbeing, emotion regulation, personal growth, positive relations with others, and self-acceptance [30]. In a similar study, re- 
searchers have indicated that people who were optimistic and thought positively regulated their emotions successfully, and they, compared to others, were less susceptible to negative interpretations of environmental events in times of aggression or anger [31].

Hence, as MS patients' quality of life is affected by the severity, duration of the disease, and drugs they take, it seems that promoting their quality of life is an integral and essential part of social and economic development. On the one hand, MS patients have to deal with numerous psychological disorders and issues, among which reduced positive affect and hope, increased anxiety, depression, and difficulties in regulating emotions can be mentioned due to their difficult conditions. On the other hand, considering the increasing prevalence of MS in Iran, especially in the age range of 20 to 40 years, one of the main issues for MS patients and their families is to have a desirable life. Furthermore, since positive psychology aims to improve wellbeing, identify positive aspects, and strengthen them to promote mental health, the current study sought to answer the following question:

Does positive thinking training affect emotion regulation and quality of life among patients with MS?

\section{Methods}

This quasi-experimental study followed by a pre-test/ post-test design with a follow-up (conducted a month after completing the training sessions). The current study had a statistical population, including $230 \mathrm{MS}$ patients in Zahedan City, Iran in 2015 who were all the members of Zahedan MS community. To select a sample, a voluntary sampling method was applied. The inclusion criteria of the study were suffering from MS and being able to read and write. The exclusion criteria were having mental disorders, cognitive disorders, a history of substance addiction, and other neurological disorders.

Based on their scores on the quality of life inventory and emotional self-regulation inventory, the subjects were assigned to two identical groups, i.e., an experimental group (20 people) and a control group (20 people). One month later, some subjects both in the experimental and control groups left the study. Hence, 12 people in the experimental group and 16 people in the control group filled out the follow-up questionnaires. The experimental group took part in eight 90-minute sessions of positive thinking training. Before initiating the sessions, a pre-test was conducted on both experimental and control groups. The post-test was carried out after the completion of the sessions. Moreover, a one- month follow-up was implemented. An analysis of covariance was applied for data analysis.

Contents and objectives of the sessions were adopted and expanded from a treatment protocol proposed by Seligman et al. [32] in the field of positive thinking. The goal of these sessions was to improve the subjects' levels of quality of life and emotion regulation (Table 1). It was attempted to hold these sessions in the forms of question-and-answer and group discussion. At the end of each session, a homework assignment was provided for the participants to accomplish until the next session. The contents of these sessions included expressing and writing down strengths, explaining the methods of using those strengths in life, acknowledging and writing thank you notes, experiencing the enjoyment of the present, improving relationships with others, promoting hope and targeting, growing capabilities in a new way, and focusing on positive emotions.

To analyze the data, we used the analysis of covariance. Data collection tools were inventories on quality of life and emotion self-regulation.

The data collecting tool in this study was a two-part questionnaire. The first part was the quality of life inventory. This self-report inventory was developed by Ware and Sherbourne in 1992 to evaluate the quality of life and health by investigating two dimensions of physical health (physical functioning, limitations due to physical issues, physical pain, and general health) and mental health (vitality, social functioning, role limitations due to emotional issues, and mental health). Therefore, it assesses the subject's health status by eight different subscales [33].

A low score on each subscale indicates a problem in the relevant field and the highest score shows the absence of a problem. The minimum score is 36 and the maximum 161. The Cronbach alpha coefficients of the quality of life inventory were reported between $61 \%$ and $93 \%$ [34]. In Iran, the internal consistency of this inventory was $87 \%$ [33]. Also, correlation coefficients amongst its eight subscales and the scores of the physical and mental dimensions were acceptable [33]. In the current study, its Cronbach alpha coefficient was found 0.74 . In the second part, the emotional self-regulation inventory was used. The self-regulation scale includes 25 items to measure selfregulation in five areas of positive performance, controllability, a revelation of feelings and needs, determination, and wellbeing-seeking. The items are rated on a 5-point Likert-type scale, from 1 to 5 [35]. 
Table 1. A summary of the structure and content of therapy sessions

\begin{tabular}{|c|c|c|}
\hline Session & Content and Activities of Each Session & Objective \\
\hline First & $\begin{array}{l}\text { Becoming familiar with the subjects, stating the objectives of holding these } \\
\text { sessions, talking about the subjects' strengths, and writing down those } \\
\text { strengths }\end{array}$ & Preparation \\
\hline Second & $\begin{array}{c}\text { Talking about methods of applying the subjects' strengths in their daily lives } \\
\text { and taking notes on positive life events }\end{array}$ & Identifying personal capabilities \\
\hline Third & $\begin{array}{l}\text { Discussing and talking about gratitude and writing down thank you letters to } \\
\text { friends }\end{array}$ & $\begin{array}{l}\text { Creating positive emotions and men- } \\
\text { tioning blessings }\end{array}$ \\
\hline Fourth & $\begin{array}{l}\text { Discussing and talking about the experience of enjoying the present by focus- } \\
\text { ing on the present }\end{array}$ & $\begin{array}{l}\text { Enjoying the present and good things } \\
\text { in life }\end{array}$ \\
\hline Fifth & $\begin{array}{l}\text { Discussing and talking about constructive and active responsiveness and } \\
\text { creating relationships with other people }\end{array}$ & $\begin{array}{l}\text { Training a responsive style and im- } \\
\text { proving relationships with others }\end{array}$ \\
\hline Sixth & $\begin{array}{l}\text { Talking about personality traits and values which the subjects wish to have in } \\
\text { the future }\end{array}$ & Increasing hope and considering goals \\
\hline Seventh & Talking about positive capabilities and methods of developing such abilities & Using capabilities in an innovative way \\
\hline Eighth & $\begin{array}{l}\text { Talking about positive thinking, choosing a favorite practice from those } \\
\text { provided in the previous sessions, and discussing it }\end{array}$ & $\begin{array}{l}\text { Increasing positive emotions and } \\
\text { reviewing the previous sessions }\end{array}$ \\
\hline
\end{tabular}

MRE

The minimum score for a subject on the scale is 25 and the maximum 125 . Using a Cronbach alpha coefficient, the validity of the Persian version of this inventory was examined and reported as $0.93,0.91$, and 0.92 , respectively for the whole scale, male subjects, and female subjects, indicating a high internal consistency of the scale. Correlation coefficients between the scores of some subjects ( 77 female and 63 male subjects) in two tests conducted with a two-week interval were calculated for the whole scale as $\mathrm{r}=0.86$, male subjects $\mathrm{r}=0.84$, and female subjects $\mathrm{r}=0.84[35,36]$.

\section{Results}

The sample included $28 \mathrm{MS}$ patients with an age range of 17 to 58 years. The mean age of the experimental group was 33.75 years and the mean age of the control group was 28.95 years. About $70 \%$ of the patients in the experimental group and $90 \%$ of the patients in the control group were in the age range of 17 to 37 years and $30 \%$ of the patients in the experimental group and $10 \%$ of the patients in the control group were in the age range of 38 to 58 years. About $45 \%$ of the patients in the experimental group and $55 \%$ of the patients in the control group were married and $55 \%$ of the patients in the experimental group and $45 \%$ of the patients in the control group were single. Also, $45 \%$ of the patients in the experimental group and $35 \%$ of the patients in the control group were male and $55 \%$ of the patients in the experimental group and $65 \%$ of the patients in the control group were female.

Their educational status varied from a middle school diploma to an MA degree. In this regard, $5 \%$ of the patients in the experimental group and $15 \%$ of the patients in the control group had a middle school diploma; $15 \%$ of the patients in the experimental group and $25 \%$ of the patients in the control group had a high school diploma. Also, 10\% of the patients in the experimental group and $15 \%$ of the patients in the control group had a BA degree. Finally, $70 \%$ of the patients in the experimental group and $45 \%$ of the patients in the control group had an MA degree.

To answer the research question, we used the analysis of covariance. To examine the assumption of the equality of variances in the pre-test, post-test, and one-month follow-up, we employed the Levene's test, which is a presumption for conducting the analysis of covariance. Given that the significance level of the Levene's test was more than $5 \%(\mathrm{P} \geq 0.05)$, the data did not violate the assumption of the equality of variances and the analysis of covariance could be applied.

The results of the Kolmogorov-Smirnov indicate that the significance levels for all the variables, i.e., the scores of emotion regulation and quality of life (physical and 
Table 2. Results of examining the homogeneity of the regression slope

\begin{tabular}{|c|c|c|c|c|c|c|c|c|c|c|}
\hline \multirow[b]{2}{*}{ Variables } & \multicolumn{5}{|c|}{ Post-test } & \multicolumn{5}{|c|}{ Follow-up } \\
\hline & $\begin{array}{l}\text { Type III } \\
\text { Sum of } \\
\text { Squares }\end{array}$ & df & $\begin{array}{l}\text { Mean } \\
\text { Square }\end{array}$ & $\mathbf{F}$ & Sig. & $\begin{array}{l}\text { Type III Sum } \\
\text { of Squares }\end{array}$ & df & $\begin{array}{l}\text { Mean } \\
\text { Square }\end{array}$ & $\mathbf{F}$ & Sig. \\
\hline Emotion regulation & 475.95 & 1 & 475.95 & 1.18 & 0.09 & 17.89 & 1 & 17.89 & 0.10 & 0.74 \\
\hline $\begin{array}{l}\text { Physical dimension (qual- } \\
\text { ity of life) }\end{array}$ & 114.81 & 1 & 114.81 & 2.77 & 0.09 & 36.71 & 1 & 36.71 & 1.64 & 0.21 \\
\hline $\begin{array}{l}\text { Mental dimension (quality } \\
\text { of life) }\end{array}$ & 245.59 & 1 & 245.59 & 3.62 & 0.07 & 73.17 & 1 & 73.17 & 1.19 & 0.28 \\
\hline
\end{tabular}

Table 3. Mean $\pm S D$ of scores on emotion regulation in the experimental and control groups

\begin{tabular}{ccccc}
\hline & & & Mean \pm SD & \\
Variable & Group & Pre-test & Post-test & Follow-up \\
\cline { 3 - 5 } & Experimental & $75.55 \pm 8.78$ & $93.11 \pm 15.40$ & $103.00 \pm 17.21$ \\
\hline \multirow{2}{*}{$\begin{array}{c}\text { Emotion regulation } \\
\text { Quality of life (the physical } \\
\text { dimension) }\end{array}$} & Control & $85.76 \pm 13.27$ & $78.70 \pm 8.82$ & $74.88 \pm 8.89$ \\
\multirow{2}{*}{$\begin{array}{c}\text { Quality of life (the mental } \\
\text { dimension) }\end{array}$} & Control & $31.83 \pm 6.82$ & $34.22 \pm 4.94$ & $37.83 \pm 3.76$ \\
\hline
\end{tabular}

MRA

Table 4. Results of the analysis of covariance scores of emotional regulations in both groups

\begin{tabular}{rccccccccc}
\hline Variable & Subscales & $\begin{array}{c}\text { Sum of } \\
\text { Squares }\end{array}$ & df & $\begin{array}{c}\text { Mean of } \\
\text { Squares }\end{array}$ & F & Sig. & $\begin{array}{c}\text { Eta- } \\
\text { Squared }\end{array}$ & $\begin{array}{c}\text { Test } \\
\text { Power }\end{array}$ \\
\hline \multirow{2}{*}{ Post-test } & Pre-test & 23.74 & 1 & 23.74 & 0.14 & 0.70 & 0.004 & 0.06 \\
& Group & 1331.05 & 1 & 1331.05 & 8.10 & 0.008 & 0.20 & 0.78 \\
Follow-up & Pre-test & 230.59 & 1 & 230.59 & 1.39 & 0.24 & 0.05 & 0.20 \\
& Group & 4136.65 & 1 & 4136.65 & 25.04 & 0.001 & 0.49 & 0.99 \\
\hline
\end{tabular}

URA

mental dimensions) are more than 0.5 ; therefore, the distribution of the relevant variables is normal.

The results of Levene's test indicate that the significance levels for all the variables, i.e., the scores of emotion regulation and quality of life (physical and mental dimensions) obtained by the experimental and control groups, are more than 0.5 ; therefore, the assumption of the equality of variances of the data is observed.

The results presented in Table 2 indicate that the interactions of all variables in the post-test and follow-up at the levels of the experimental and control groups are not significant; therefore, the assumption of homogeneity of the variances is observed.

The results presented in Table 3 indicate that the mean scores on emotional regulation and quality of life (the physical and mental dimensions) obtained by the experimental group in the pre-test, post-test, and follow-up increased compared with the control group.

The results presented in Table 4 show a significant difference between the mean post-test score $\left(\mathrm{F}_{1,35}=8.10\right.$, $\left.\mathrm{P} \leq 0.008, \eta^{2}=0.20\right)$ and the mean follow-up score $\left(\mathrm{F}_{1,28}=\right.$ $\left.25.04, \mathrm{P} \leq 0.001, \eta^{2}=0.49\right)$. Hence, the mean post-test and 
Table 5. Results of the analysis of covariance scores of quality of life in both groups

\begin{tabular}{|c|c|c|c|c|c|c|c|c|c|}
\hline \multicolumn{2}{|c|}{ Dimensions } & Subscales & $\begin{array}{c}\text { Sum of } \\
\text { Squares }\end{array}$ & df & $\begin{array}{r}\text { Mean of } \\
\text { Squares }\end{array}$ & $\mathbf{F}$ & Sig. & $\begin{array}{c}\text { Eta- } \\
\text { Squared }\end{array}$ & $\begin{array}{c}\text { Test } \\
\text { Power }\end{array}$ \\
\hline \multirow{4}{*}{ Physical } & \multirow{2}{*}{ Post-test } & Pre-test & 33.12 & 1 & 33.12 & 1.69 & 0.20 & 0.04 & 0.24 \\
\hline & & Group & 198.31 & 1 & 198.31 & 10.16 & 0.003 & 0.23 & 0.87 \\
\hline & \multirow{2}{*}{$\begin{array}{l}\text { Follow- } \\
\text { up }\end{array}$} & Pre-test & 0.15 & 1 & 0.15 & 0.001 & 0.98 & 0.001 & 0.05 \\
\hline & & Group & 463.91 & 1 & 463.91 & 20.25 & 0.001 & 0.44 & 0.99 \\
\hline \multirow{4}{*}{ Mental } & \multirow{2}{*}{ Post-test } & Pre-test & 30.97 & 1 & 30.97 & 0.66 & 0.41 & 0.02 & 0.12 \\
\hline & & Group & 242.30 & 1 & 242.30 & 5.36 & 0.02 & 0.14 & 0.61 \\
\hline & \multirow{2}{*}{$\begin{array}{l}\text { Follow- } \\
\text { up }\end{array}$} & Pre-test & 0.78 & 1 & 0.78 & 0.034 & 0.85 & 0.001 & 0.05 \\
\hline & & Group & 270.90 & 1 & 270.90 & 11.84 & 0.002 & 0.32 & 0.91 \\
\hline
\end{tabular}

follow-up scores of emotion regulation are significantly higher in the experimental group than in the control group. Considering the eta-squared in the post-test and follow-up, it can be stated that, 0.20 and 0.49 of variances, respectively, are due to the effect of the independent variable (the positive thinking training).

The results presented in Table 5 show a significant difference between the mean post-test score $\left(\mathrm{F}_{1,35}=10.16\right.$, $\left.\mathrm{P} \leq 0.003, \eta^{2}=0.23\right)$ and the mean follow-up score $\left(\mathrm{F}_{1,28}=\right.$ $\left.20.25, \mathrm{P} \leq 0.001, \eta^{2}=0.44\right)$. Hence, the mean post-test and follow-up scores of the physical dimension of quality of life are significantly higher in the experimental group than in the control group. Considering the eta-squared values in the post-test and follow-up, it can be stated that, 0.23 and 0.44 of the variances are due to the effect of the independent variable, respectively (the positive thinking training). Moreover, results indicate a significant difference between the mean post-test score $\left(\mathrm{F}_{1,35}=5.36, \mathrm{P} \leq 0.02\right.$, $\left.\eta^{2}=0.14\right)$ and the mean follow-up score $\left(\mathrm{F}_{1,28}=11.84\right.$, $\left.\mathrm{P} \leq 0.002, \eta^{2}=0.32\right)$. Hence, the mean post-test and followup scores of the mental dimension of quality of life are significantly higher in the experimental group than in the control group. Considering the eta-squared values in the post-test and follow-up, it can be stated that 0.14 and 0.32 of the variances, respectively, are due to the effect of the independent variable (positive thinking training).

\section{Discussion}

Positive psychology is a new branch of psychology that attempts to study humans' strengths and happiness in a scientific way. By thinking positively, the usual ways of thinking and acting can aid people to be more flexible and do something new. The present study aimed to examine the effect of positive thinking training on emotion regulation and quality of life among MS patients.
The results showed that positive thinking training had an impact on promoting the mental and physical dimensions of quality of life. These results are consistent with the results of studies conducted by Lee et al. [16], Brannan et al. [20], Hariri and Khodami [21], Donaldson [22], Rashid et al. [23], Carver [24], Jalali et al. [25], Castillo and Egea [26], Mousavi et al. [27], Partovinia and Ashouri [28], Mohammad-Najar et al. [29], Ghiasi et al. [30], and Gordon et al. [31].

The results of a study carried out by Cohenn et al. showed that positive thinking and mental health were significantly and directly correlated [16]. In their study, Efklides and Moraitou reported that not only does positive psychology, which focuses on strengths and positive emotions, give people tools to reach a desirable level of wellbeing and a high level of quality of life without considering their conditions but also makes it possible to cope with their issues by applying hope, optimism, flexibility, and spirituality [17]. Several studies indicated that the effects of positive psychotherapy improve mental wellbeing [18].

Several studies investigated the effect of positive thinking training on various groups of patients and indicated that the training increased their resilience and quality of life [27-29]. This finding is in line with the results of the present study. Besides, the results of the current study demonstrated that positive thinking training would affect emotion regulation among MS patients. This finding is consistent with the results of some studies, among which the following can be mentioned. A study conducted by Nikmanesh and Zandvakili indicated that positive psychotherapy was effective in improving the quality of life among juvenile delinquents [19]. Research evidence suggests that using positive thinking as a treatment increases mental health and promotes positive relations and emotions, self-esteem, and happiness [21-23]. The 
results of a study carried out by Carver et al. showed a direct significant relationship between emotion regulation and positive thinking training [24]. In their study, Jalali et al. figured out that positive psychotherapy increased mental wellbeing and quality of life [25] and the results of a study conducted by Castillo and Egea demonstrated that positive thinking established positive relationships with others and created positive emotions [26].

The results obtained by Mohammad-Najar et al. showed that positive thinking training led to an increase in the scores of hope and the dimensions of quality of life (physical, mental, and social dimensions) among the drug-dependent people [29]. A study conducted by Giasi et al. demonstrated that optimism training was effective in promoting psychological well-being, emotion regulation, personal growth, positive relations with others, and self-acceptance [30]. In a similar study, Gordon et al. indicated that people who were optimistic and thought positively regulated their emotions successfully, and they, compared to others, were less susceptible to negative interpretations of environmental events in times of aggression or anger [31].

Chronic diseases, due to their effects on people's abilities and daily living, can influence all aspects of people's lives and lead to a decrease in their quality of life. When people with MS maintain their proper physical, mental, and social status, they can be satisfied with doing daily activities and internal functioning, external control, or recovery. Accordingly, all MS patients who have a positive and optimistic attitude and view towards their environment and disease can cope with uncontrollable conditions of the disease, like weakness, fatigue, and constraints caused by it. On the other hand, emotion regulation is a significant psychological factor among MS patients that affects their ability to effectively regulate their emotions and has a great impact on their psychological, physical, and interpersonal happiness. People with MS, compared with normal people, deal with more difficulties in regulating their emotions. This issue is associated with low levels of quality of life and psychological wellbeing among these people. Hence, strategies like positive thinking can increase emotion regulation by decreasing negative emotions and, subsequently, promoting the levels of quality of life and psychological wellbeing among these people. Additionally, training positive thinking skills can aid these patients to find new psychological solutions and achieve a positive and useful way of thinking; therefore, positive thinking is accompanied by good living and psychological wellbeing outcomes.

Positive people are healthier and happier and their immune systems work better compared with other people. By using more effective coping strategies such as reappraisal and problem-solving, these people can cope with psychological stress more effectively. Moreover, they can actively avoid stressful life events and create better social support networks around themselves. They have healthier lifestyles that keep them away from diseases [32].

\section{Conclusion}

Considering the results obtained from this study, positive thinking creates a set of behaviors based on satisfaction, optimism, hope, self-esteem, and self-confidence. Positive thinking is a kind of social work that is accompanied by several outcomes, including collaboration, social freshness, social consensus, positive emotions, community life, and social participation. As an emotional capital that reduces the costs of official control and supervision, it persuades people to display behaviors consistent with social values and norms. Positive thinking has several effects on people's lives, some are as follows: living with happiness, looking positively at the life, considering positive points in people and life, transferring positive energy to others, reducing mental stress, distress, and depression, and creating self-esteem. Therefore, positive thinking training can aid MS patients to regulate their emotions in a better way and promote their quality of life.

Among the limitations of this study, the following can be mentioned. Some subjects left the study, the sample population was limited to MS patients, and several variables, including drugs the patients took, and the severity and duration of the disease could not be controlled.

Concerning the results of the current study, it is recommended to conduct a positive thinking training program aimed at improving the levels of quality of life and emotion regulation among these patients in MS communities, by which these patients are supported. In addition to this training, positive thinking skills should be taught to them in a regular program in MS communities to promote the patients' quality of life and help them to regulate their emotions in a better way.

\section{Ethical Considerations}

\section{Compliance with ethical guidelines}

Ethical considerations, including obtaining the full consent of the participants and maintaining data confidentiality, were strictly observed. Also, the Ethics Committee of Zahedan Faculty of Psychology and Educational Sciences approved this study (Code: IR.USB. REC.1399.011). 


\section{Funding}

The present paper was extracted from the MA thesis of the second author, Aliebne Abitaleb Hospital, Zahedan University of Medical Sciences, Zahedan, Iran.

\section{Authors' contributions}

Study design, manuscript preparation: All authors; Data analysis, data collection: Lida Mirkazehi.

\section{Conflict of interest}

The authors declared no conflicts of interest.

\section{References}

[1] Łabuz-Roszak B, Kubicka-Baczyk K, Pierzchała K Horyniecki M, Machowska-Majchrzak A, AugustyńskaMutryn D, et al. Quality of life in multiple sclerosis-association with clinical features, fatigue and depressive syndrome. Psychiatr Pol. 2013; 47(3):433-42

[2] Sahraian MA, Khorramnia S, Ebrahim MM, Moinfar Z, Lotfi J, Pakdaman H. Multiple sclerosis inIran: A demographic study of 8,000 patients and changes over time. European Neurology. 2010; 64(6):331-6. [DOI:10.1159/000321649] [PMID]

[3] Naji SA, Bahraini S, Mannani R, Bekhradi R. [The effect of aromatherapy massage on the fatigue severity in women with Multiple Sclerosis (Persian)]. J Sabzevar Uni Med Sci. 2011; 18(3) 172-178.

[4] Yousefi AR, Shaghaghi F, Dehestani M, Barghi Irani Z. [The relationship between Quality of Life (QoL) and psychological capital with illness perception in MS patients (Persian)]. Health Psychol. 2012; 1(1):1-15.

[5] Schalock RL, Brown I, Brown R, Cummins RA, Felce D, Matikka L, Keith KD, Parmenter T. Conceptualization, measurement, and application of quality of life for persons with intellectual disabilities: Report of an international panel of experts. Ment Retard. 2002; 40(6):457-70. [DOI:10.1352/00476765(2002)040<0457:CMAAOQ>2.0.CO;2] [PMID]

[6] Kolotkin RL, Meter K, Williams GR. Quality of life and obesity. Obes Rev. 2001; 2 (4):219-9. [DOI:10.1046/j.1467789X.2001.00040.x] [PMID]

[7] Fraser C, Morgante L, Hadjimichael O, Vollmer T. A prospective study of adherence to glatiramer acetate in individuals with multiple sclerosis. J Neurosci Nurs. 2004; 36(3):120-9. [DOI: 10.1097/01376517200406000-00002]

[8] Benedict RHB, Wahling E, Bakshi R, et al. Predicting quality of life in multiple sclerosis: For physical disability, fatigue, cognition, mood disorder, personality, and behavior change. J Neurol Sci. 2005; 231(1-2):29-34. [DOI:10.1016/j. jns.2004.12.009] [PMID]
[9] Myberg L. [Forgiveness as a mechanism of self-regulation An ego depletion model (English)]. [??. Thesis]. United States: University of Richmond; 2011.

[10] Butt MM, Sanam F, Gulzar SH, Yahya F. Cognitive emotional regulation and forgiveness. J Interdiscipl Contemp Res Bus. 2013; 4(12):769-92.

[11] Seligman MEP, Csikszentmihalyi M. Positive Psychology: An introduction American. Am Psychol. 2000; 55(1):5-14 [DOI:10.1037/0003-066X.55.1.5] [PMID]

[12] Snyder CR, Lopez SJ, editors. Handbook of positive psychology. England: Oxford University Press; 2001.

[13] Carr A. Positive Psychology: The Science of Happiness and Human Strength. New York: Brunner-Routledge; 2004 [DOI:10.4324/9780203506035]

[14] Froman L. Positive psychology in the workplace. (Electronic Version). Journal of Psychology Department 2010; 17:59-69. [DOI:10.1007/s10804-009-9080-0]

[15] Sin NL, Lyubomirsky S. Enhancing well-being and alleviating depressive symptoms with positive psychology interventions: A practice-friendly meta-analysis. J Clin Psychol. 2009; 65 (5):467-87. [DOI:10.1002/jclp.20593] [PMID]

[16] Lee V, Robin Cohen S, Edgar L, Laizner AM, Gagnon AG Meaning-making intervention during breast or colorecta cancer treatment improves self-esteem, optimism, and selfefficacy. Soc Sci Med. 2006; 62 (12): 3133-45. [DOI:10.1016/j. socscimed.2005.11.041] [PMID]

[17] Efklides A, Moraitou D. A positive psychology perspective on quality of life. Social Indicators Res Ser. 2013; 51: 1-295. [DOI:10.1007/978-94-007-4963-4]

[18] Blanc J, Boyer L, Le Coz P, Auquier P. Metacognition: Towards a new approach to quality of life. Qual Life Res. 2014 23(2):467-75. [DOI:10.1007/s11136-013-0485-7] [PMID]

[19] Nikmanesh Z, Zandvakili M. [The effect of positive thinking training on quality of life, depression, stress and anxiety in delinquent juveniles (Persian)]. Posit Psychol. 2015; 1(2): 53-64.

[20] Brannan Brannan D, Biswas-Diener R, Mohr CD, Mortazavi S, Stein N. Friends and family: A cross-cultural investigation of social support and subjective well-being among college students. J Posit Psychol. 2013; 8(1):65-75. [DOI:10.1080/ 17439760.2012.743573]

[21] Hariri M, Khodami N. A study of the efficacy of teaching happiness Based on the Fordyce method to elderly people on their life expectancy. Procedia Soc Behav Sci. 2011; 30(Supplement C):1412-5. [DOI:10.1016/j.sbspro.2011.10.275]

[22] Rashid T. Positive psychotherapy: A strength-based approach. J Posit Psychol. 2015; 10:(1):25-40. [DOI:10.1080/17 439760.2014.920411]

[23] Donaldson SI, Dollwet M, Rao MA. Happiness, excellence, and optimal human functioning revisited: Examining the peerreviewed literature linked to positive psychology. J Posit Psychol. 2015; 10(3): 185-95. [DOI:10.1080/17439760.2014.943801]

[24] Carver SC. Self-control and optimism are distinct and complementary strengths. Pers Individ Dif. 2014; 66(3):24-6. [DOI:10.1016/j.paid.2014.02.041] 
[25] Jalali N, khaloie G, Mirmahdi SR. [Effectiveness of positive psychotherapy, psychological well-Being and quality of life in spouses of veterans with mental disorders (Persian)]. Paper presented at: 2nd International Conference on Modern Research in the Humanities. 12 June 2014; Tehran, Iran. https:/ /www. civilica.com/Paper-MRHCONF02-MRHCONF02_115.html

[26] Castillo ID, Ortega Egea JM. Too positive to change Examining optimism bias as a barrier to media effects on environmental activism. J Environ Psychol. 2015; 43:216-25. [DOI:10.1016/j.jenvp.2015.07.004]

[27] Mousavi E, Esmaeili A, Shahid Saless S. The effect of positive thinking on quality of life and resiliency of cancer patients. Razavi Int J Med. 2015; 3(3): 24-8. [DOI:10.17795/rijm27122]

[28] Partovinia R, Ashouri A. Effectiveness of teaching the positive thinking on the quality of; if of married old women. Int J Humanit Cult Stud. 2016; 4(4):1548-58.

[29] Mohammad-Najar N, Khoshnevis E, Banisi, P. Effectiveness of positive thinking skills training on the hope and quality of life of drug-dependent people. Addict Health. 2017; 9(3):120-8.

[30] Ghiasi E , Tabatabaee T, Nasri M. [Effect of optimism training on emotion regulation and psychological wellbeing in undergraduate students of University of Birjand, in 2014-2015 (Persain)]. Pajouhan Sci J. 2016; 14(4):27-37. [DOI:10.21859/psj-140427]

[31] Gordon NS, Chesney SA, Reiter K. Thinking positively: Optimism and emotion regulation predict interpretation of ambiguous information. J Cogent Psychol. 2016; 3:1-13. [DO I:10.1080/23311908.2016.1195068]

[32] Seligman M E, Steen TA, Park N, Peterson C. Positive psychology progress: Empirical validation of interventions. Am Psychol. 2005; 60(5):410-21. [DOI:10.1037/0003066X.60.5.410] [PMID]

[33] Hadi N, Malek makan L. [Study Quality of life and Health levels of elementary schoolteacher in Shiraz (Persian)]. Hormozgan Med Mag. 2006; 10(4):387-92. [DOI:10.5812/semj.84762]

[34] Barker-Collo SL. Quality of life in multiple sclerosis: Does information-processing speed have an independent effect? Arch Clin Neuropsychol. 2006; 21(2):167-74. [DOI:10.1016/j. acn.2005.08.008] [PMID]

[35] Marque's MJ, Ibanez MI, Ruiperez MA, Ortet-Fabregat G The Self-Regulation Inventory (SRI): Psychometric properties of a health related coping measure. Pers Individ Dif. 2005; 39:1043-54. [DOI:10.1016/j.paid.2005.02.030]

[36] Ghalehban M. [Examination and comparison of Alexithymia and self- regulation in patients with substance abuse disorder and normal individual (Persian)]. Procedia Soc Behav Sci. 2011; 30:38-42. [DOI:10.1016/j.sbspro.2011.10.008] 
This Page Intentionally Left Blank 